\section{Trends in quality of care and dying perceived by family caregivers of nursing home residents with dementia 2005-2019}

Palliative Medicine

1-10

(C) The Author(s) 2021

(c) (i)

Article reuse guidelines:

sagepub.com/journals-permissions DOI: $10.1177 / 02692163211030831$ journals.sagepub.com/home/pmj

(S)AGE

\author{
Maartje S Klapwijk ${ }^{1,2}$ iD, Sascha R Bolt ${ }^{3,4}$ iD, Jannie A (Nienke) Boogaard ${ }^{1}$, \\ Maud ten Koppel ${ }^{5}$, Marie-José HE Gijsberts ${ }^{6}$, Carolien van Leussen?, \\ B. Anne-Mei The ${ }^{7,8}$, Judith MM Meijers ${ }^{3,4,9}$, Jos MGA Schols ${ }^{3,4}$, \\ H Roeline W Pasman ${ }^{5}$, Bregje D Onwuteaka-Philipsen ${ }^{10}$, Luc Deliens ${ }^{6}$, \\ Lieve Van den Block ${ }^{6}$, Bart Mertens ${ }^{11}$, Henrica CW de Vet ${ }^{12}$, \\ Monique AA Caljouw ${ }^{1}$, Wilco P Achterberg ${ }^{1}$ \\ and Jenny van der Steen ${ }^{1,13}$
}

\begin{abstract}
Background: Dementia palliative care is increasingly subject of research and practice improvement initiatives.

Aim: To assess any changes over time in the evaluation of quality of care and quality of dying with dementia by family caregivers. Design: Combined analysis of eight studies with bereaved family caregivers' evaluations 2005-2019.

Setting/participants: Family caregivers of nursing home residents with dementia in the Netherlands $(n=1189)$ completed the Endof-Life in Dementia Satisfaction With Care (EOLD-SWC; quality of care) and Comfort Assessment in Dying (EOLD-CAD, four subscales; quality of dying) instruments. Changes in scores over time were analysed using mixed models with random effects for season and facility and adjustment for demographics, prospective design and urbanised region.

Results: The mean total EOLD-SWC score was 33.40 (SD 5.08) and increased by 0.148 points per year ( $95 \%$ Cl, 0.052-0.244; adjusted 0.170 points $95 \% \mathrm{Cl}, 0.055-0.258$ ). The mean total EOLD-CAD score was 30.80 (SD 5.76) and, unadjusted, there was a trend of decreasing quality of dying over time of -0.175 points $(95 \% \mathrm{Cl},-0.291$ to -0.058$)$ per year increment. With adjustment, the trend was not significant ( -0.070 EOLD-CAD total score points, $95 \% \mathrm{Cl},-0.205$ to 0.065 ) and only the EOLD-CAD subscale 'Well being' decreased. Conclusion: We identified divergent trends over 14 years of increased quality of care, while quality of dying did not increase and wellbeing in dying decreased. Further research is needed on what well-being in dying means to family. Quality improvement requires continued efforts to treat symptoms in dying with dementia.
\end{abstract}

\title{
Keywords
}

Dementia, geriatrics, palliative care, nursing homes, quality of health care, end-of-life care

\footnotetext{
${ }^{1}$ Department of Public Health and Primary Care, Leiden University Medical Center, Leiden, The Netherlands

${ }^{2}$ Huis op de Waard, Marente, Huis op de Waard, Leiden, The Netherlands ${ }^{3}$ Department of Health Services Research, Faculty of Health Medicine and Lifesciences, CAPHRI School for Public Health and Primary Care, Maastricht University, Maastricht, The Netherlands

${ }^{4}$ Living Lab in Ageing and Long-Term Care, Maastricht, The Netherlands 5Zorginstituut Nederland, Diemen, North Holland, The Netherlands ${ }^{6}$ End-of-Life Care Research Group, Vrije Universiteit Brussel (VUB) and Ghent University, Brussels, Belgium

${ }^{7}$ Tao of Care, Amsterdam, The Netherlands

${ }^{8}$ Department Sociology, Faculty of Social Sciences, Vrije Universiteit Amsterdam, Amsterdam, The Netherlands

${ }^{9}$ Zuyderland Care, Zuyderland Medical Center, Sittard-Geleen, The Netherlands
}

${ }^{10}$ Department of Public and Occupational Health, Amsterdam UMC, Locatie VUmc, Amsterdam, The Netherlands

${ }^{11}$ Department of Medical Statistics and Bioinformatics, Leiden University Medical Center, Leiden, The Netherlands

${ }^{12}$ Department of Epidemiology and Data Science, Amsterdam UMC, Location VU University Amsterdam Public Health Research Institute, Amsterdam, The Netherlands

${ }^{13}$ Department of Primary and Community Care, Radboud university medical center, Nijmegen, The Netherlands

\section{Corresponding author:}

Maartje S Klapwijk, Department of Public Health and Primary Care, Leiden University Medical Center, P.O. Box 9600, Leiden, South Holland 2300 RC, The Netherlands.

Email: m.s.klapwijk@lumc.nl 


\section{What is already known about the topic?}

- Dementia is an incurable condition and in Western countries, most people with dementia die in nursing homes.

- The knowledge base concerning palliative care for people with dementia has expanded.

- Bereaved family caregivers' experiences and perceptions of the dying phase and the quality of care of their relatives are relevant, as they need to live on with memories.

\section{What this paper adds?}

- This study shows that from 2005 to 2019 , family caregivers increasingly appreciated the quality of care provided to their relative with dementia dying in a nursing home.

- Family caregivers' evaluation of quality of dying, however, did not improve, indicating that families did not perceive fewer symptoms over time, and even perceived lower well-being while dying (items on serenity, peace and calm).

\section{Implications for practice, theory or policy?}

- Monitoring trends in the palliative care for people with dementia may aid our understanding of the influence of policy and societal developments.

- Research is needed to explain trends and help to decrease symptom burden and improve quality of dying for people with dementia.

\section{Introduction}

In Western European countries such as the UK and the Netherlands, most people with dementia eventually move to a nursing home, where they reside until death. ${ }^{1-3}$ Nursing home residents may benefit from palliative care with a focus on comfort and quality of life..$^{4,5}$ The cognitive impairment associated with moderate or advanced dementia often leads to limited verbal expression of needs. This complicates the assessment of specific palliative care needs and addressing of symptoms.6,7 Family caregivers of people with dementia fulfil important roles as spokespersons, care partners, informants and proxy decision-makers. ${ }^{8-11}$ Their role continues after nursing home admission. ${ }^{12,13}$ Staff should acknowledge the family caregivers' role in the care for people with dementia, especially at the end of life. ${ }^{14-16}$ Families' experiences with end-of-life care and their interactions with professional caregivers potentially influence their post-bereavement outcomes. ${ }^{17}$ 'How people die remains in the memories of those who live on' is a famous quote in palliative care literature. ${ }^{18}$ Memories of family members reflect the dying experience and may expose specific points for improvement in end-of-life care. ${ }^{19}$ Family caregivers are important judges of the quality of end-of-life care provided to residents with dementia and of their quality of dying. ${ }^{20,21}$ Validated instruments are available to measure quality of care and quality of dying from the family perspective. ${ }^{22,23}$

A small study that investigated data from 2005 to 2010 showed a positive trend in families' reports of quality of end-of-life care for nursing home residents with dementia. ${ }^{24}$ Exploring such trends can aid our understanding of how the experiences of family caregivers with end-of-life care may have changed, which informs future initiatives to improve palliative and end-of-life care. The present study examines trends in quality of care and quality of dying up to 2019 as judged by family caregivers of residents with dementia in Dutch nursing homes. Various national initiatives aimed to improve knowledge on palliative care in the Netherlands over the last decade. Therefore, the hypothesis is that these trends over a period in which development of dementia palliative care continued, are positive.

\section{Methods}

\section{Study population}

Data from eight studies conducted in the Netherlands in overlapping time windows between 2005 and 2019 were combined for trend analyses (Table 1).22,24-30 For seven of the studies, it concerned a secondary analysis of data collected to address various research questions (Supplement). The main goal of the eighth and most recent study was to enhance assessment of trends over time. Some studies employed nationally representative sampling, whereas other studies were regional. All studies collected data retrospectively, and one study also collected data prospectively (Table 1). ${ }^{22,24-30}$ Data collected during any intervention condition were excluded. The data concern 1189 persons with dementia who died in 117 nursing home facilities. One facility contributed to two studies (studies 1 and 3, Table 1). The family caregivers who were the primary contact persons were invited to complete a questionnaire; within 1.5-2 months after death in most studies, 


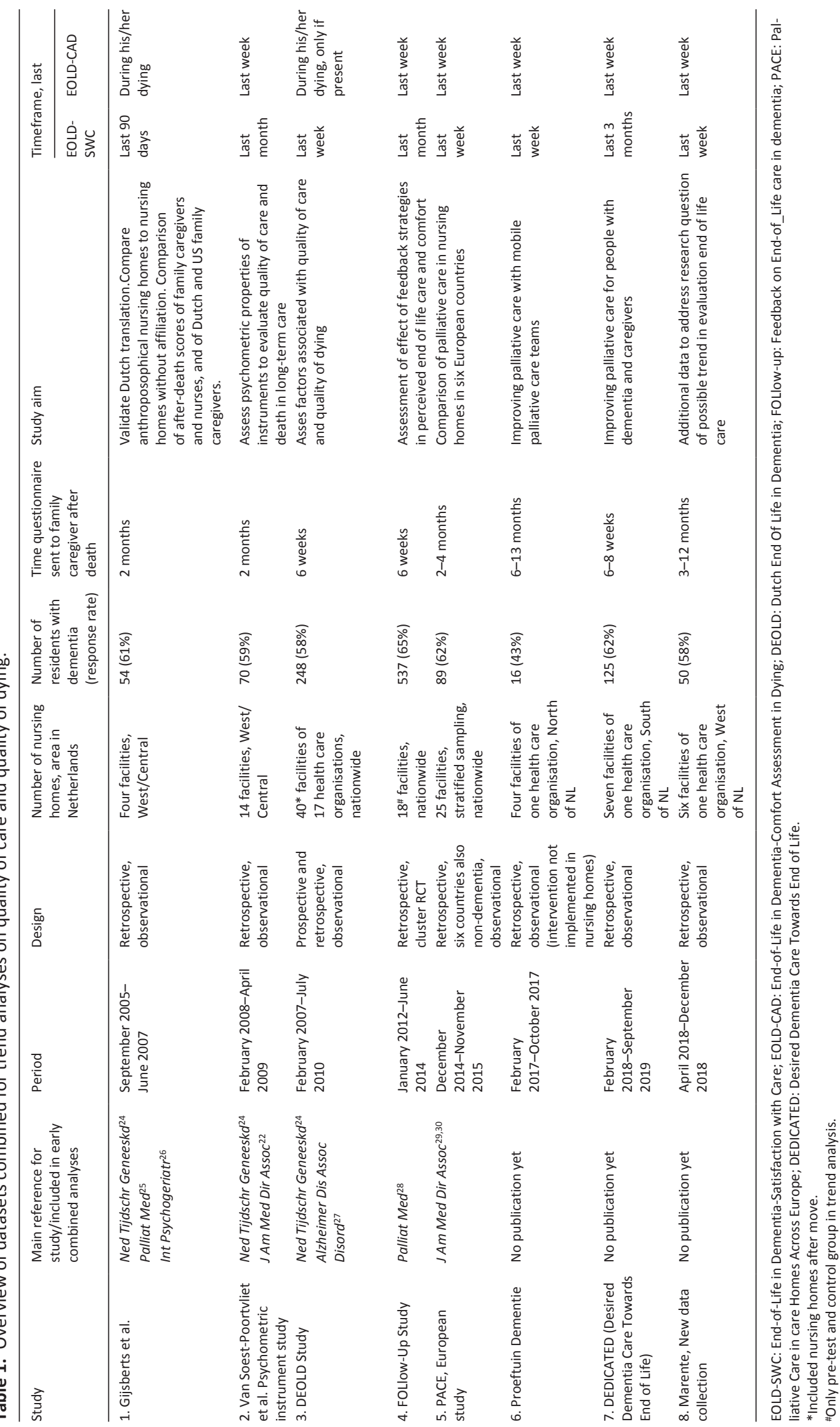


and up to about a year after death in two studies (studies 6 and 8, Table 1). All nursing home residents included in these studies received medical care by a certified elderly care physician. ${ }^{31}$

\section{Instruments}

Quality of end-of-life care was measured with the Endof-Life in Dementia Satisfaction With Care (EOLD-SWC) instrument. ${ }^{20,23}$ It has the most favourable psychometric properties as compared to other such instruments and it comprises 10 items regarding experiences on quality of care from the perspective of the family caregiver. ${ }^{22}$ The items cover decision-making, communication, understanding the resident's condition and medical care. The response options are: strongly disagree, disagree, agree and strongly agree. Three items are negatively phrased statements, which require reverse coding before summing to total scores that range from 10 to 40. A higher score indicates better quality of end-of-life care.

The End-of-Life in Dementia Comfort Assessment in Dying (EOLD-CAD) ${ }^{20}$ was used to measure quality of dying. ${ }^{23,32}$ The EOLD-CAD comprises 14 items on symptoms such as pain, shortness of breath, choking, and fear. It also includes three positive items in a 'Well being' subscale. This subscale consists of items serenity, peace and calm, which require reverse coding. The three response options are: a lot, somewhat and not at all. Total scores range from 14 to 42, a higher score indicating a better perceived quality of dying. Most studies (6 out of 8 ) referred to the last week of life. One study used a skip pattern for the EOLD-CAD if the relative was not present during dying, setting a higher bar with regard to actual presence to observe comfort (Table 1).

\section{Cognition}

All residents had a physician's diagnosis of dementia and resided in a psychogeriatric unit. Studies 1, 2, 3 and 5 (Table 1) included staff assessment using the Bedford Alzheimer Nursing Severity-Scale (BANS-S) to measure the severity of the dementia in the months before death. BANS-S scores range from 7 to 28 . A score of 17 or higher represents severe dementia. ${ }^{33,34}$ In studies 1 to 5 , staff assessed whether residents were fully dependent in eating. Full eating dependence indicates very severe cognitive impairment and is equal to the highest level of impairment on the Cognitive Performance Scale (CPS 6). ${ }^{35,36}$

\section{Trend analysis}

The EOLD-SWC and EOLD-CAD scores in the combined dataset were analysed with mixed models, using time of death relative to the first death in the first study as the independent variable. The models included random effects for season (as Comment 17 seasonality in cause of death might vary between years) and for clustering of residents within nursing homes. ${ }^{37,38}$ In study 7 , only the month of death was available due to privacy regulations, and we imputed the 14th for February and the 15th for other months. We provide $95 \%$ confidence intervals around the estimate for time. Models were adjusted for characteristics of residents (age and gender), and family caregivers (gender, relationship to resident), region (urbanised Western and central region of the country with greater staffing problems versus other region), and design (prospective enrolment of residents versus retrospectively after death). We conducted sensitivity analyses with additional adjustment for severity of dementia measured with the BANS-S or the eating dependence item (CPS 6) and family caregiver's age. We also added a quadratic term for time to assess the fit of a non-linear model.

Descriptive statistics were used for respondent characteristics. If less than one third of EOLD items missed, the items were imputed with the patient item mean to generate a total score. All analyses were performed in SPSS Inc, version 25, 2017, IBM, USA.

\section{Results}

The mean age of the residents was 85.5 years; $67.9 \%$ were female (Table 2). A little over half $(53.7 \%)$ had severe dementia and almost a third (29.4\%) were fully dependent in eating (no data available for the studies covering 2018 and 2019). Distributions of age, gender and dementia severity were fairly homogeneous between the eight studies (Table 2). Of the family caregivers, the majority were female $(62.8 \%)$, and most were sons or daughters (in-law) of the resident (65.8\%). The EOLD-SWC (quality of care) mean total ranged from 31.9 to 34.1 , and the EOLDCAD (quality of dying) mean total score ranged from 27.2 to 33.3 across studies (Table 3 ). The correlation between the EOLD-SWC and the EOLD-CAD for quality of dying was weak $(+0.27, p<0.001)$.

Figure $1(a)$ shows unadjusted quality of care means per 2 years; the curve is steeper in earlier years and flattens over time when variable error bars are taken into consideration. The EOLD-SWC total score significantly increased by 0.148 points per year $(\mathrm{Cl}, 0.052-0.244)$, and in the adjusted model the trend was an additional 0.170 points per year ( $\mathrm{Cl}, 0.055-0.285)$ (Table 4). The EOLD-CAD total score significantly decreased by -0.175 points per year $(\mathrm{Cl},-0.291$ to -0.058 ; Table 4 and Figure $1(\mathrm{~b}))$ but in the adjusted model the trend was not significant with a decrease of -0.070 points per year $(\mathrm{Cl},-0.205$ to 0.065$)$. The difference of EOLD-CAD with the adjusted model $(-0.070$ vs -0.175 unadjusted; Table 4$)$ was driven by adjustment for prospective versus retrospective design. The subscale 'Well Being' significantly decreased by -0.076 points per year $(\mathrm{Cl},-0.114$ to -0.039$)$ in the unadjusted model, and in the adjusted model by -0.073 points 


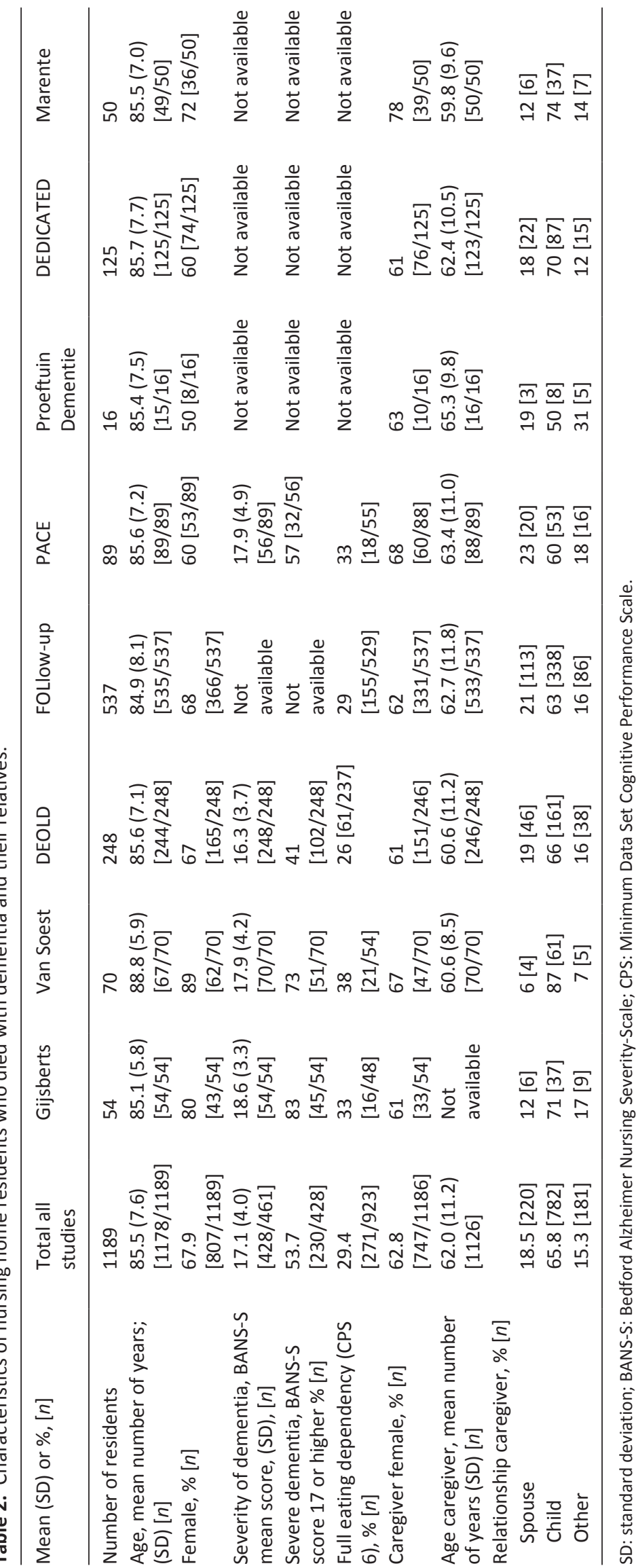


Table 3. Total scores for quality of care (EOLD-SWC; $n=1169)$ and quality of dying (EOLD-CAD; $n=903$ ) across studies.

\begin{tabular}{llccc}
\hline Study/project, mean (SD) & EOLD-SWC & $n /$ total $n$ & EOLD-CAD & $n /$ total $n$ \\
\hline 1. Gijsberts & $31.9(4.7)$ & $54 / 54$ & $32.0(5.4)$ & $52 / 54$ \\
2. Van Soest-Poortvliet & $32.1(5.8)$ & $68 / 70$ & $30.7(5.3)$ & $59 / 70$ \\
3. DEOLD & $32.6(5.3)$ & $242 / 248$ & $33.3(5.9)$ & $88 / 90$ \\
4. FOLlow-up & $34.1(4.8)$ & $535 / 537$ & $30.6(5.6)$ & $466 / 537$ \\
5. PACE & $33.8(5.2)$ & $86 / 89$ & $29.7(5.6)$ & $80 / 89$ \\
6. Proeftuin Dementie & $30.2(6.3)$ & $16 / 16$ & $27.2(7.2)$ & $13 / 16$ \\
7. DEDICATED & $33.7(5.0)$ & $118 / 125$ & $30.6(6.2)$ & $101 / 125$ \\
8. Marente & $33.4(4.8)$ & $50 / 50$ & $30.8(5.5)$ & $44 / 50$ \\
\hline
\end{tabular}

EOLD-SWC: End-of-Life in Dementia-Satisfaction with Care; EOLD-CAD: End-of-Life in Dementia-Comfort Assessment in Dying.

per year $(\mathrm{Cl},-0.119$ to -0.028$)$. The other subscale scores showed no significant trend. Trend models in EOLD-SWC and EOLD-CAD for separate studies are shown in Supplemental Figures S1 and S2.

The sensitivity analyses showed similar estimates. A quadratic term for time was significant for the EOLD-SWC in both the unadjusted $(p=0.002)$ and the adjusted model ( $p<0.001$; Supplemental Figure S3). A quadratic term for change over time was not significant in the unadjusted model for EOLD-CAD ( $p=0.096)$ or the adjusted model $(p=0.223)$.

\section{Discussion}

\section{Main findings}

This study investigated trends in family caregivers' assessments of quality of end-of-life care and quality of dying of nursing home residents with dementia in the Netherlands. From 2005 to 2019, quality of care improved, in particular in the earlier years. Quality of dying did not significantly change in adjusted analyses that included adjustment for prospective design, but scores on the subscale 'Well being' nevertheless decreased, also after adjustment.

The statistically significant changes are relevant longterm changes as they may represent ongoing change, and a 2.4 increase in EOLD-SWC total score, for example, nears 3 used in power calculations. ${ }^{39}$ The progressive and terminal nature of dementia and the complex care needs that accompany dementia underpin a palliative approach to care. ${ }^{5,40}$ The evidence-base for palliative dementia care is still small but will expand over the coming years. ${ }^{41}$ The early increase in quality of care in the Netherlands may be related to political developments in palliative care from the late 1990s onward. ${ }^{42}$ A 1997 policy programme aimed to integrate palliative care into the regular healthcare system, to increase practitioners' skills and knowledge. ${ }^{43}$ In Dutch national dementia plans, however, palliative or end-of-life care is not mentioned. ${ }^{44}$ Treatments for symptom relief in nursing home residents with dementia increased in 2006-2007 compared to the late 1990s. ${ }^{45}$
Reasons for this increase, according to physicians, included growing attention and awareness regarding symptom relief, clearer treatment goals and a focus on quality of life..$^{45}$ Palliative care specialists are consulted for residents in Dutch nursing homes with dementia, in only $2.5 \%$ of the cases. ${ }^{46}$ Compared to five other European countries, however, the treating physician in Dutch nursing homes is involved in palliative care more often (in $98.8 \%$ of the cases). ${ }^{30,47}$

In the context of increasing quality of end-of-life care as perceived by family and increasing awareness regarding palliative care as perceived by physicians, ${ }^{45}$ finding no improvement on the quality of dying scale and a decline on the 'Well being' subscale is counterintuitive. Further, scores on the quality of care items, regarding measures taken to improve comfort and regarding nursing assistance showed the highest increase. Other studies also found weak to moderate associations between quality of care evaluated by families and perceived quality of dying. ${ }^{48,49}$ An interesting artefact may have been introduced by a design issue, with a negative trend for a prospective design (Supplemental Figures S1 and S2). Repeated completion of questionnaires on symptom burden in the prospective study may also have increased family caregivers' awareness of symptoms in the dying phase. These family caregivers may have been prompted to report more symptoms.

Nevertheless, controlled for design, the trend was also negative for the subscale 'Well Being' that comprises the items 'serenity', 'peace' and 'calm'. Family caregivers may hold negative perceptions about the end of life with dementia as being undignified, especially in Western societies where autonomy is highly valued..$^{50}$ Increasing media exposure and public campaigns on 'living well with dementia', in combination with the Dutch debate on the acceptability of euthanasia in dementia in recent years might influence such perceptions. Lemos Dekker ${ }^{50}$ found that family caregivers of nursing home residents with dementia may feel powerless due to a lack of control over relief of their relatives' suffering. Higher expectations and standards of care, and increased focus on control and 


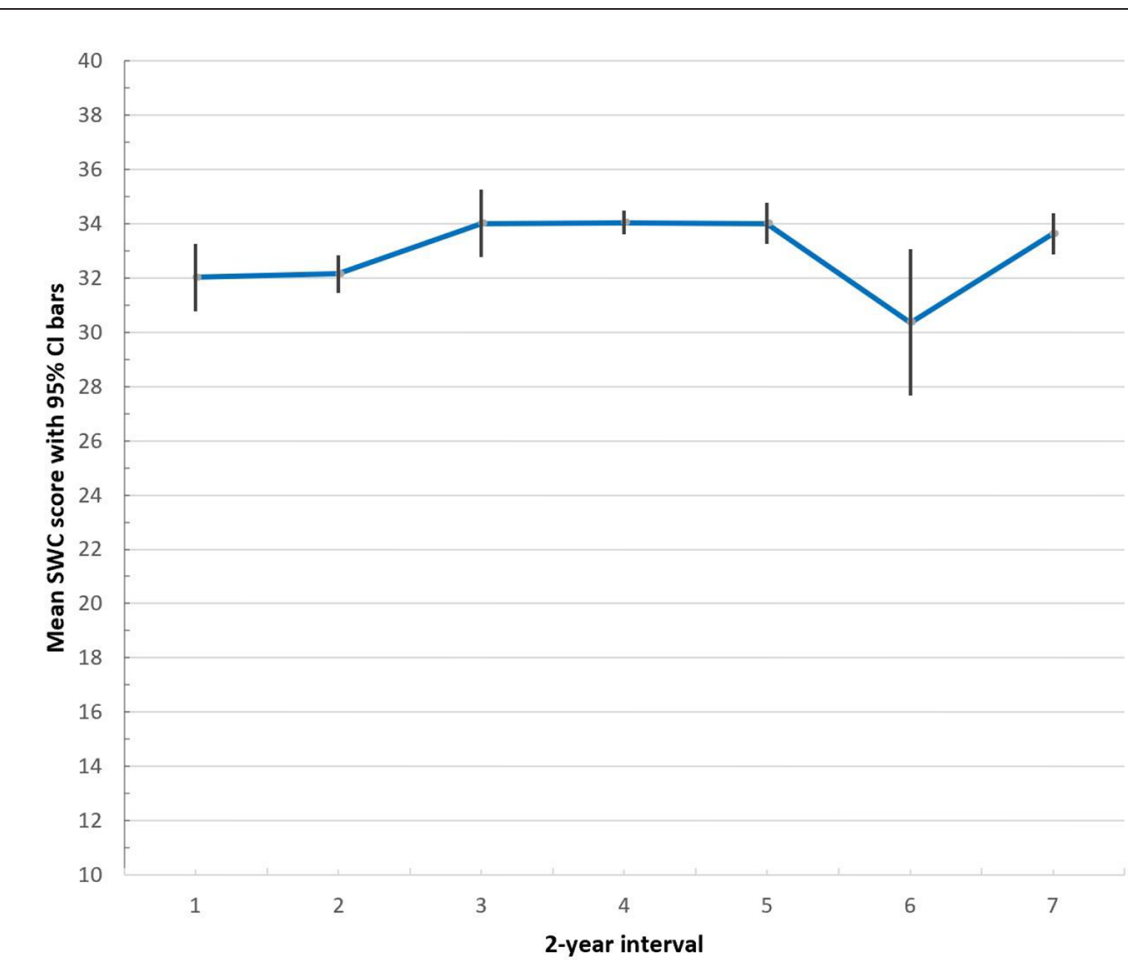

(a)

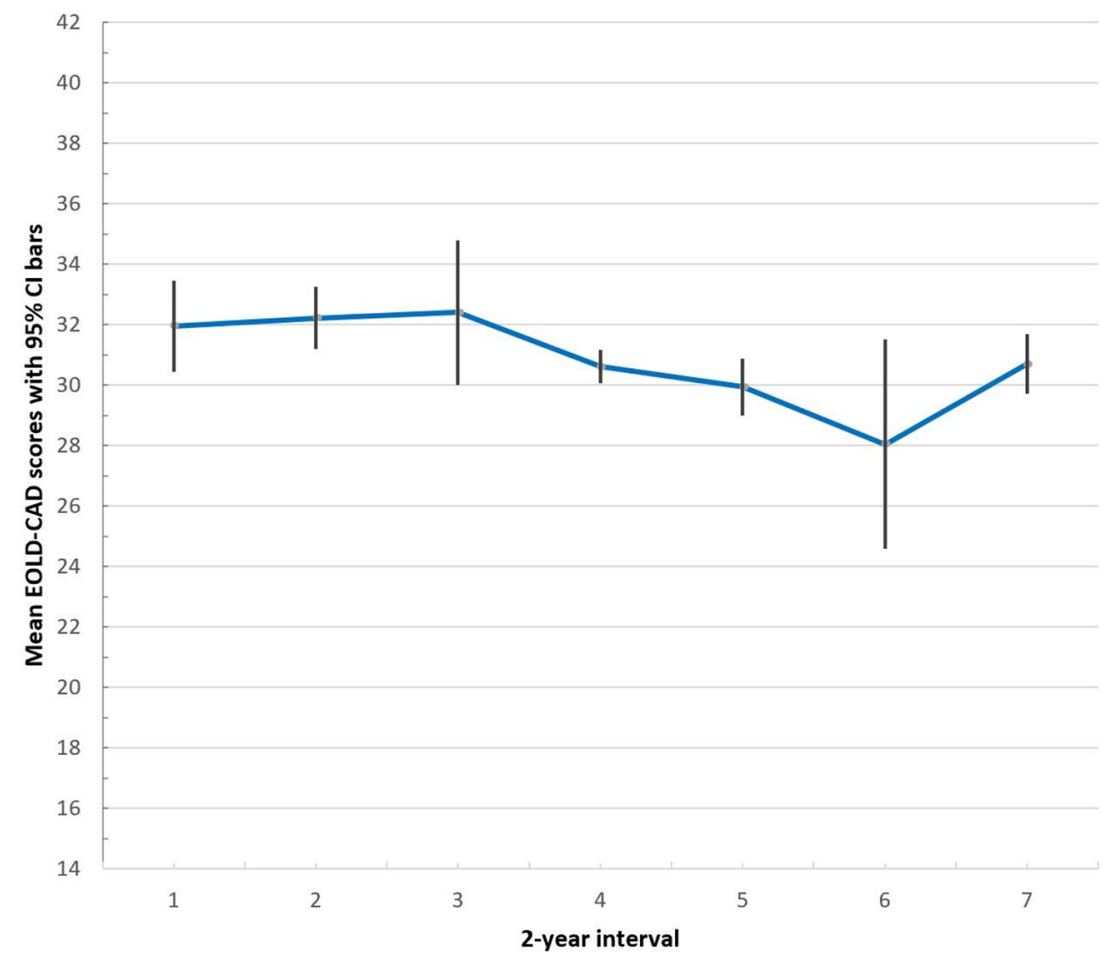

(b) 2-year interval: $1=$ Sept 2005-Aug 2007 2= Sept 2007-Aug 2009 $3=$ Sept 2009-Aug 2011 $4=$ Sept 2011-Aug 2013 $5=$ Sept 2013-Aug 2015 $6=$ Sept 2015-Aug 2017 7= Sept 2017-Aug 2019 2-year interval: $1=$ Sept 2005-Aug 2007 $2=$ Sept 2007-Aug 2009 $3=$ Sept 2009-Aug 2011 4= Sept 2011-Aug 2013 $5=$ Sept 2013-Aug 2015 $6=$ Sept 2015-Aug 2017 $7=$ Sept 2017-Aug 2019

Figure 1. (a) EOLD-SWC means per 2-year intervals with 95\% $\mathrm{Cl}$ bars and (b) EOLD-CAD means per 2-year intervals with $95 \% \mathrm{Cl}$ bars. EOLD-SWC: End-of-Life in Dementia-Satisfaction with Care; EOLD-CAD: End-of-Life in Dementia-Comfort Assessment in Dying; Cl: confidence interval. 
Table 4. Trends in total and item quality of care scores (EOLD-SWC) and in total and subscale quality of dying Scores (EOLD-CAD).

\begin{tabular}{|c|c|c|c|}
\hline & Mean (SD) $[n]$ & $\begin{array}{l}\text { Trend; coefficient } \\
(95 \%-\mathrm{Cl}) \text { unadjusted }\end{array}$ & $\begin{array}{l}\text { Trend; coefficient } \\
(95 \%-\mathrm{Cl}) \text { adjusted }\end{array}$ \\
\hline EOLD-SWC totala & $33.40(5.08)[1169]$ & $0.148(0.052$ to 0.244$)$ & 0.170 (0.055 to 0.285$)$ \\
\hline a. I felt fully involved in all decision making & $3.41(0.66)[1171]$ & $0.017(0.005$ to 0.029$)$ & $0.017(0.002$ to 0.032$)$ \\
\hline $\begin{array}{l}\text { b. I would probably have made different } \\
\text { decisions if I had had more information }\end{array}$ & $3.30(0.73)[1137]$ & $0.006(-0.008$ to 0.019$)$ & $0.011(-0.006$ to 0.027$)$ \\
\hline $\begin{array}{l}\text { c. All measures were taken to keep my } \\
\text { relative comfortable }\end{array}$ & $3.47(0.66)[1167]$ & $0.024(0.012$ to 0.037$)$ & 0.030 (0.016 to 0.045$)$ \\
\hline $\begin{array}{l}\text { d. The health care team were sensitive to } \\
\text { my needs and feelings }\end{array}$ & $3.35(0.65)[1146]$ & $0.019(0.007$ to 0.031$)$ & $0.015(0.001$ to 0.030$)$ \\
\hline $\begin{array}{l}\text { e. I did not really understand my relative's } \\
\text { condition }\end{array}$ & $3.35(0.78)[1150]$ & $0.011(-0.002$ to 0.024$)$ & $0.010(-0.005$ to 0.026$)$ \\
\hline $\begin{array}{l}\text { f. I always knew which doctor or nurse was } \\
\text { in charge of my relative's care }\end{array}$ & $3.03(0.78)[1165]$ & $0.014(-0.000$ to 0.029$)$ & $0.011(-0.006$ to 0.029$)$ \\
\hline $\begin{array}{l}\text { g. I felt that my relative got all necessary } \\
\text { nursing assistance }\end{array}$ & $3.42(0.66)[1170]$ & $0.019(0.007$ to 0.031$)$ & $0.026(0.011$ to 0.040$)$ \\
\hline $\begin{array}{l}\text { h. I felt that all medication issues were } \\
\text { clearly explained to me }\end{array}$ & $3.27(0.71)[1155]$ & $0.016(0.004$ to 0.029$)$ & 0.021 (0.005 to 0.036$)$ \\
\hline $\begin{array}{l}\text { i. My relative was receiving all treatments } \\
\text { or interventions that he or she could } \\
\text { benefit from }\end{array}$ & $3.38(0.66)[1164]$ & $0.015(0.004$ to 0.027$)$ & $0.016(0.002$ to 0.030$)$ \\
\hline $\begin{array}{l}\text { j. I feel that my relative needed better } \\
\text { medical care at the end of his or her life }\end{array}$ & $3.42(0.76)$ [1159] & $0.005(-0.008$ to 0.019$)$ & $0.010(-0.006$ to 0.026$)$ \\
\hline EOLD-CAD total ${ }^{b}$ & $30.80(5.76)[903]$ & $-0.175(-0.291$ to -0.058$)$ & $-0.070(-0.205$ to 0.065$)$ \\
\hline $\begin{array}{l}\text { 1. Physical distress }{ }^{c} \text { (item 1, 2, 3, 4, score } \\
\text { range 4-12) }\end{array}$ & $8.34(2.09)[935]$ & $-0.037(-0.079$ to 0.004$)$ & $0.00001(-0.048$ to 0.048$)$ \\
\hline $\begin{array}{l}\text { 2. Dying symptoms }{ }^{d} \text { (item } 4 \text { (part of two } \\
\text { subscales), } 5,6,7 \text {, score range } 4-12 \text { ) }\end{array}$ & $8.85(2.20)[922]$ & $-0.017(-0.059$ to 0.025$)$ & $0.017(-0.032$ to 0.067$)$ \\
\hline $\begin{array}{l}\text { 3. Emotional distresse (item } 8,9,10,11 \text {, } \\
\text { score range } 4-12 \text { ) }\end{array}$ & $9.54(2.19)$ [904] & $-0.061(-0.104$ to -0.019$)$ & $-0.026(-0.077$ to 0.025$)$ \\
\hline $\begin{array}{l}\text { 4. Well being (item } 12,13,14 \text {, score range } \\
\text { 3-9) }\end{array}$ & $6.14(1.98)$ [908] & $-0.076(-0.114$ to -0.039$)$ & $-0.073(-0.119$ to -0.028$)$ \\
\hline
\end{tabular}

EOLD-SWC: End-of-Life in Dementia-Satisfaction with Care; EOLD-CAD: End-of-Life in Dementia-Comfort Assessment in Dying; SD: standard deviation; $\mathrm{Cl}$ : confidence interval, italics and bold $=p<0.05$.

EOLD-SWC item scores are presented because the total score trend is significant.

Cronbach's $\alpha$ : aEOLD-SWC total: 0.90; ${ }^{b} E O L D-C A D$ total: 0.83; 'EOLD-CAD subscale Physical distress: 0.62; dEOLD-CAD subscale Dying symptoms: 0.68;

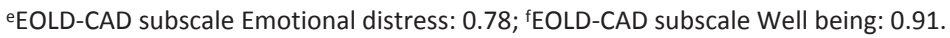

dignity might explain a decrease in their assessment of well-being in dying, while their assessment of concrete symptoms remained unchanged. Future research is needed to disentangle what well-being in dying means to families.

\section{Strengths and limitations}

This study used perspectives from more than 1000 family caregivers of nursing home residents with dementia, over a period of 14 years. It does not evaluate a single reform as there were various initiatives to improve palliative care. Identifying of individual items that did or did not change further enhances the study's relevance to clinical practice. The EOLD-SWC has strong psychometric properties, whereas there is some ambiguity about the psychometric properties of the EOLD-CAD regarding feasibility, validity and reliability. ${ }^{22,51}$ Although the EOLD-CAD items all assess aspects of quality of dying, the instrument does not cover the full concept of quality of dying, which may include aspects that are more difficult to assess such as retaining identity or dignity. ${ }^{52}$ Nonetheless, other such measures do not perform better or properties are unknown. The EOLDSWC and EOLD-CAD scales have been widely used after an early comparison of psychometric properties, ${ }^{22}$ which facilitates comparison between countries. ${ }^{30,53}$ This study was limited to the Netherlands, but its EOLD scores are fairly representative for recent European research. ${ }^{30}$ Sample sizes, recruitment methods and the period before death referred to in the EOLD instruments varied between the individual studies in the analyses. There may be residual confounding by unmeasured confounders. However, any confounding by dementia severity is unlikely as adjusted estimated were unchanged in sensitivity analyses. 


\section{Conclusion}

This study observed a positive trend in family caregivers' assessments of the quality of end-of-life care for nursing home residents with dementia over a period of 14 years. Family caregivers' assessments of quality of dying did not change with regard to symptoms during dying, but according to their assessments the well-being during dying decreased over time. There may be a growing gap between family caregivers' expectations and actual symptoms and well-being at the end of life. These observations call for further monitoring of quality perceived by family and research to investigate contemporary ideas about what constitutes a 'good and comfortable death' at the end of life with dementia.

\section{Authors' contribution}

MK, WA and JvdS developed the original concept for this study. MK and JvdS analysed the data. BM advised on the statistical analysis. MK, SB and JvdS wrote the manuscript, and all authors reviewed and commented on the subsequent drafts. All authors read and approved the final manuscript.

\section{Declaration of conflicting interests}

The author(s) declared the following potential conflicts of interest with respect to the research, authorship, and/or publication of this article: All authors have completed the ICMJE uniform disclosure form at www.icmje.org/coi_disclosure.pdf and declare: no support from any organization for the submitted work; no financial relationships with any organizations that might have an interest in the submitted work in the previous three years; no other relationships or activities that could appear to have influenced the submitted work.

\section{Funding}

The author(s) received no financial support for the research, authorship, and/or publication of this article.

\section{Data availability statement}

The data sets generated and analyzed during the current study are not publicly available. The combined data are available upon reasonable request and permission granted from the owners of all datasets.

\section{ORCID iDs}

Maartje S Klapwijk (iD https://orcid.org/0000-0002-4961-2978

Sascha R Bolt iD https://orcid.org/0000-0003-1570-0432

\section{Supplemental material}

Supplemental material for this article is available online.

\section{References}

1. Honinx E, van Dop N, Smets $T$, et al. Dying in long-term care facilities in Europe: the PACE epidemiological study of deceased residents in six countries. BMC Public Health 2019; 19: 1199.
2. Reyniers T, Deliens L, Pasman HR, et al. International variation in place of death of older people who died from dementia in 14 European and non-European countries. $J$ Am Med Dir Assoc 2015; 16: 165-171.

3. Joling KJ, Janssen O, Francke AL, et al. Time from diagnosis to institutionalization and death in people with dementia. Alzheimer Dement 2020; 16: 662-671.

4. Froggatt $\mathrm{K}$, Payne $\mathrm{S}$, Morbey $\mathrm{H}$, et al. Palliative care development in European care homes and nursing homes: application of a typology of implementation. J Am Med Dir Assoc 2017; 18: 550.e7-550.e14.

5. van der Steen JT, Radbruch L, Hertogh CM, et al. White paper defining optimal palliative care in older people with dementia: a Delphi study and recommendations from the European Association for Palliative Care. Palliat Med 2014; 28: 197-209.

6. Erel M, Marcus EL and Dekeyser-Ganz F. Barriers to palliative care for advanced dementia: a scoping review. Ann Palliat Med 2017; 6: 365-379.

7. Blackstone KA and Cobbs EL. Palliative care for persons with dementia. J Am Geriatr Soc 2021; 69: 1461-1462.

8. Graneheim UH, Johansson A and Lindgren BM. Family caregivers' experiences of relinquishing the care of a person with dementia to a nursing home: insights from a metaethnographic study. Scand J Caring Sci 2014; 28: 215-224.

9. Bern-Klug $M$ and Forbes-Thompson S. Family members' responsibilities to nursing home residents: "she is the only mother I got". J Gerontol Nurs 2008; 34: 43-52.

10. Lord K, Livingston G and Cooper C. A systematic review of barriers and facilitators to and interventions for proxy decision-making by family carers of people with dementia. Int Psychogeriatr 2015; 27: 1301-1312.

11. Givens JL, Kiely DK, Carey K, et al. Healthcare proxies of nursing home residents with advanced dementia: decisions they confront and their satisfaction with decision-making. J Am Geriatr Soc 2009; 57: 1149-1155.

12. Brodaty $\mathrm{H}$ and Donkin $\mathrm{M}$. Family caregivers of people with dementia. Dialogues Clin Neurosci 2009; 11: 217-228.

13. Ross MM, Carswell A and Dalziel WB. Family caregiving in long-term care facilities. Clin Nurs Res 2001; 10: 347-363; discussion 64-68.

14. Boogaard JA, van der Steen JT, de Boer AH, et al. How is end-of-life care with and without dementia associated with informal caregivers' outcomes? Am J Hosp Palliat Care 2019; 36: 1008-1015.

15. Bolt S, van der Steen J, Schols J, et al. What do relatives value most in end-of-life care for people with dementia? Int J Palliat Nurs 2019; 25: 432-442.

16. Reid RC and Chappell NL. Family involvement in nursing homes: are family caregivers getting what they want? J Appl Gerontol 2017; 36: 993-1015.

17. Shuter $P$, Beattie $E$ and Edwards $H$. An exploratory study of grief and health-related quality of life for caregivers of people with dementia. Am J Alzheimers Dis Other Demen 2014; 29: 379-385.

18. Saunders C. Pain and impending death. In: Wall PD and Melzack R (eds) Textbook of pain. New York, NY: Churchill Livingstone, 1984, pp.472-478.

19. Teno JM, Clarridge BR, Casey V, et al. Family perspectives on end-of-life care at the last place of care. JAMA 2004; 291: 88-93. 
20. Volicer L, Hurley AC and Blasi ZV. Scales for evaluation of end-of-life care in dementia. Alzheimer Dis Assoc Disord 2001; 15: 194-200.

21. McPherson $\mathrm{CJ}$ and Addington-Hall JM. Judging the quality of care at the end of life: can proxies provide reliable information? Soc Sci Med 2003; 56: 95-109.

22. van Soest-Poortvliet MC, van der Steen JT, Zimmerman S, et al. Selecting the best instruments to measure quality of end-of-life care and quality of dying in long term care. J Am Med Dir Assoc 2013; 14: 179-186.

23. van Soest-Poortvliet MC, van der Steen JT, Zimmerman S, et al. Psychometric properties of instruments to measure the quality of end-of-life care and dying for long-term care residents with dementia. Qual Life Res 2012; 21: 671-684.

24. van der Steen JT, van Soest-Poortvliet MC, Gijsberts MJ, et al. [Improved end-of-life care for patients with dementia: greater family satisfaction and possibly greater end-oflife comfort]. Ned Tijdschr Geneeskd 2013; 157: A5324.

25. van der Steen JT, Gijsberts MJ, Knol DL, et al. Ratings of symptoms and comfort in dementia patients at the end of life: comparison of nurses and families. Palliat Med 2009; 23: 317-324.

26. van der Steen JT, Gijsberts MJ, Muller MT, et al. Evaluations of end of life with dementia by families in Dutch and U.S. nursing homes. Int Psychogeriatr 2009; 21: 321-329.

27. van der Steen JT, Ribbe MW, Deliens L, et al. Retrospective and prospective data collection compared in the Dutch End Of Life in Dementia (DEOLD) study. Alzheimer Dis Assoc Disord 2014; 28: 88-94.

28. Boogaard JA, de Vet HC, van Soest-Poortvliet MC, et al. Effects of two feedback interventions on end-of-life outcomes in nursing home residents with dementia: a clusterrandomized controlled three-armed trial. Palliat Med 2018; 32: 693-702.

29. Van den Block L, Smets T, van Dop N, et al. Comparing palliative care in care homes across Europe (PACE): protocol of a cross-sectional study of deceased residents in $6 \mathrm{EU}$ countries. J Am Med Dir Assoc 2016; 17: 566.e1-566.e7.

30. Pivodic L, Smets T, Van den Noortgate N, et al. Quality of dying and quality of end-of-life care of nursing home residents in six countries: an epidemiological study. Palliat Med 2018; 32: 1584-1595.

31. Koopmans RT, Lavrijsen JC, Hoek JF, et al. Dutch elderly care physician: a new generation of nursing home physician specialists. J Am Geriatr Soc 2010; 58: 1807-1809.

32. Stewart AL, Teno J, Patrick DL, et al. The concept of quality of life of dying persons in the context of health care. J Pain Symptom Manage 1999; 17: 93-108.

33. Appollonio I, Gori C, Riva G, et al. Assessing early to late stage dementia: the TSI and BANS-S scales in the nursinghome. Int J Geriatr Psychiatry 2005; 20: 1138-1145.

34. Volicer L, Hurley AC, Lathi DC, et al. Measurement of severity in advanced Alzheimer's disease. J Gerontol 1994; 49: M223-M226.

35. Morris JN, Fries BE, Mehr DR, et al. MDS Cognitive Performance Scale. J Gerontol 1994; 49: M174-M182.

36. van der Steen JT, Volicer L, Gerritsen DL, et al. Defining severe dementia with the Minimum Data Set. Int J Geriatr Psychiatry 2006; 21: 1099-1106.
37. Fitzmaurice GM, Laird NM and Ware JM. Applied longitudinal analysis. Hoboken, NJ: John Wiley \& Sons, 2012.

38. Molenberghs $G$ and Verbeke $G$. A review on linear mixed models for longitudinal data, possibly subject to dropout. Stat Modelling 2001; 1: 235-269.

39. Boogaard JA, van Soest-Poortvliet MC, Anema JR, et al. Feedback on end-of-life care in dementia: the study protocol of the FOLlow-up project. BMC Palliat Care 2013; 12: 29.

40. van der Steen JT, Lemos Dekker N, Gijsberts MHE, et al. Palliative care for people with dementia in the terminal phase: a mixed-methods qualitative study to inform service development. BMC Palliat Care 2017; 16: 28.

41. Murphy E, Froggatt K, Connolly S, et al. Palliative care interventions in advanced dementia. Cochrane Database Syst Rev 2016; 12: CD011513.

42. van Soest F. De organisatie van de palliatieve zorg in Nederland. In: Berendsen A and van Soest F (eds) Inzichten in de palliatieve zorg. Houten: Bohn Stafleu van Loghum, 2014, pp.3-14.

43. Francke AL and Kerkstra A. Palliative care services in The Netherlands: a descriptive study. Patient Educ Couns 2000; 41: 23-33.

44. Nakanishi M and van der Steen JT. National dementia plans to address escalating global palliative care needs. Palliat Med 2020; 34: 966-967.

45. van der Steen JT, Meuleman-Peperkamp I and Ribbe MW. Trends in treatment of pneumonia among Dutch nursing home patients with dementia. J Palliat Med 2009; 12: 789-795.

46. van der Steen JT, Deliens L, Koopmans R, et al. Physicians' perceptions of suffering in people with dementia at the end of life. Palliat Support Care 2017; 15: 587-599.

47. Ten Koppel M, Onwuteaka-Philipsen BD, Van den Block L, et al. Palliative care provision in long-term care facilities differs across Europe: results of a cross-sectional study in six European countries (PACE). Palliat Med 2019; 33: 1176-1188.

48. Liu LM, Guarino AJ and Lopez RP. Family satisfaction with care provided by nurse practitioners to nursing home residents with dementia at the end of life. Clin Nurs Res 2012; 21: 350-367.

49. Engel SE, Kiely DK and Mitchell SL. Satisfaction with end-oflife care for nursing home residents with advanced dementia. J Am Geriatr Soc 2006; 54: 1567-1572.

50. Lemos Dekker N. Moral frames for lives worth living: managing the end of life with dementia. Death Stud 2018; 42: 322-328.

51. Kupeli N, Candy B, Tamura-Rose G, et al. Tools measuring quality of death, dying, and care, completed after death: systematic review of psychometric properties. Patient 2018; 12: 183-197.

52. Nishimura M, Dening KH, Sampson EL, et al. Cross-cultural conceptualisation of a good end of life with dementia: a meta-qualitative study. In: Alzheimer disease international conference 2020, 2020, pp.64-65. https://www.alzint. org/u/ADI-2020-Abstract-Book.pdf

53. Cohen LW, van der Steen JT, Reed D, et al. Family perceptions of end-of-life care for long-term care residents with dementia: differences between the United States and the Netherlands. J Am Geriatr Soc 2012; 60: 316-322. 